\title{
Intensification of the Rate of Diffusion-controlled Electrochemical and Catalytic Reactions at a Helical Coil by a Fixed Bed Turbulence Promoter
}

\author{
M. A. El-Naggar, ${ }^{a,{ }^{*}}$ M. S. Mansour, ${ }^{a}$ A. H. El-Shazly, ${ }^{a, b}$ \\ S. A. Nosier, ${ }^{a}$ Y. A. El-Taweel, ${ }^{a}$ and G. H. Sedahmed ${ }^{a}$ \\ ${ }^{a}$ Chemical Engineering Department, Alexandria University, \\ Alexandria, Egypt \\ ${ }^{b}$ Chemical and Petrochemicals Engineering Department, \\ Egypt-Japan University of Science and Technology, \\ El-Arab City, Alexandria, Egypt
}

doi: 10.15255/CABEQ.2018.1299

Original scientific paper

Received: February 13, 2018

Accepted: September 10, 2018

Intensifications of the rate of diffusion-controlled electrochemical and catalytic reactions taking place at the outer surface of a helical coil imbedded in an inert fixed bed of cylinders acting as turbulence promoters was studied using the electrochemical technique. The technique involved measuring the limiting current of the cathodic reduction of $\mathrm{K}_{3} \mathrm{Fe}(\mathrm{CN})_{6}$ in a large excess of $\mathrm{NaOH}$ as a supporting electrolyte.

The variables studied were solution velocity, packing cylinder diameter, helical coil tube diameter, and physical properties of the solution. The rate of mass transfer at the outer surface of the coil was found to increase with increasing solution velocity and decreasing packing cylinder diameter, helical coil tube diameter was found to have a little effect on the rate of mass transfer. The data were correlated with the dimensionless equation

$$
S h=7.14 \cdot 10^{-4} S c^{0.33} \operatorname{Re}^{0.52}\left(\frac{d_{p}}{d}\right)^{-2.32}
$$

Implication of the above equation for the design and operation of the present reactor was pointed out. The potential importance of using the inner surface of the coil as a builtin heat transfer facility for conducting exothermic electrochemical and catalytic reactions requiring rapid cooling was highlighted. The possibility of using multiple imbedded coaxial helical coils of different coil diameter in practical catalytic reactors to increase their rate of production was noted.

Keywords:

mass transfer, heat transfer, helical coils, fixed beds, turbulence promoters

\section{Introduction}

Recently, there has been substantial progress in the design of heterogeneous reactors (electrochemical reactors and catalytic reactors) used to conduct exothermic catalytic and electrochemical reactions, especially those involving heat-sensitive material that need rapid cooling. Previous studies dealing with such reactions have used heat exchanger/reactor, which consists of an array of vertical or horizontal tubes; the outer surface of the tubes acts as a catalyst support or electrode, while the inner surface of the tubes acts as a heat exchanger through which a coolant is passed to absorb excess heat generated on the outside surface ${ }^{1-4}$. Such reactors with a built-in heat transfer facility would reduce the capital costs of the process owing to the elimination of the need for an external heat exchanger. Exam-

"Corresponding author, e-mail: m.abbas.elnaggar@alexu.edu.eg ples of exothermic reactions that need rapid temperature control include electro-organic synthesis and immobilized cell biochemical reactions. According to Baily and Ollis ${ }^{5}$, cells use chemical energy quite efficiently; like any real process, some of the energy in the substrate is released as heat. This metabolic heat generation dictates cooling requirements for bioreactors which harbor the cells. During electro-organic synthesis, a considerable amount of heat $(Q)$ is generated as a result of the conversion of electrical energy used to overcome polarization at the two electrodes and ohmic drop in the solution into heat, according to the equation ${ }^{6,7}$

$$
Q=I\left(\eta_{\text {cathode }}+\eta_{\text {anode }}+I R-\frac{T \Delta S}{z F}\right) .
$$

This heat may adversely affect reaction selectivity and product yield besides decomposing heat-sensitive products. In case of exothermic cata- 
lytic reactions, rapid heat removal is essential in order to (i) increase the equilibrium yield of the product, especially in case of reversible reactions, (ii) eliminate hot spots which lead to catalyst deactivation and loss of selectivity and yield, (iii) tame runaway reactions.

The aim of the present work was to intensify the rate of mass and heat transfer (by analogy) at the outer surface of a helical coil electrode or catalyst support by imbedding the helical coil in an inert fixed bed of cylinders acting as a turbulence promoter. The use of inert fixed bed of particles as turbulence promoter has been employed with other electrode geometries, such as vertical cylinders and plates to enhance the rate of diffusion-controlled reactions $^{8-11}$. The advantages of using helical coils as a heat exchanger/reactor over straight tubes are: (i) helical coils are more compact and hence have a higher area per unit volume, which gives rise to high-space time yield, (ii) the rate of heat transfer inside helical coils is much higher than in straight tubes $^{12}$. Although the heat and mass transfer behavior of the outer and inner sides of helical coils was studied under different hydrodynamic conditions $^{12-16}$, no previous studies have been reported on the use of inert fixed beds to enhance the rate of heat or mass transfer at the coil outer surface. The mass transfer behavior of the outer surface of a helical tube was studied using the electrochemical technique, which involves measuring the limiting current of the cathodic reduction of $\mathrm{K}_{3} \mathrm{Fe}(\mathrm{CN})_{6}$ in a large excess of $\mathrm{NaOH}$ as a supporting electrolyte ${ }^{17}$.

\section{Materials and methods}

The apparatus (Fig. 1) consisted of the reactor, flow circuit, and electrical circuit. The reactor was a plexiglass column of $0.18 \mathrm{~m}$ diameter and $0.7 \mathrm{~m}$ height, it was divided into three sections: the inlet section had a height of $0.25 \mathrm{~m}$ and was packed with glass spheres of $0.016 \mathrm{~m}$ diameter, the working section which contained the cell had a height of $0.2 \mathrm{~m}$. The cell consisted of a nickel-plated copper helical coil cathode of diameter $0.09 \mathrm{~m}$ and a pitch of $0.005 \mathrm{~m}$. Three helical coils with tube diameters $0.006,0.01$, and $0.016 \mathrm{~m}$ were used. For the sake of uniform current distribution at the helical coil cathode, two stainless steel anodes were used, a central rod anode, and a cylindrical anode lining the reactor wall around the coil. The cell was imbedded in an inert fixed bed of plastic cylinders, three different packing cylinder diameters were used: $0.008,0.01$, and $0.012 \mathrm{~m}$, cylinders were packed in the bed at random, cylinder aspect ratio (length/diameter) $=1$, bed porosity $(\epsilon)$ for cylinder diameter $0.008,0.01$, $0.012 \mathrm{~m}$ was $0.47,0.482$, and 0.514 , respectively.

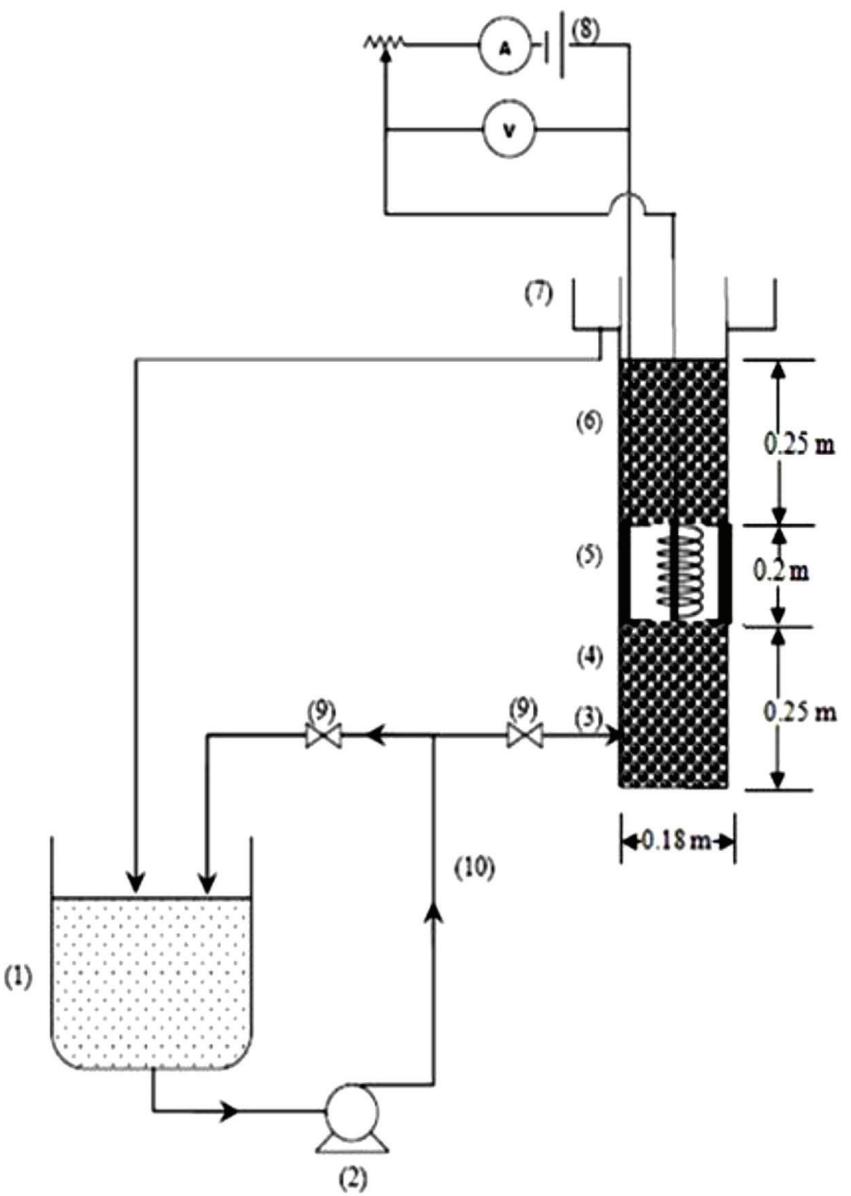

Fig. 1 - Experimental set up

(1) Glass storage tank; (2) Plastic centrifugal pump; (3) Solution inlet; (4) Inlet calming section; (5) Working section (packed bed containing the electrolytic cell); (6) Outlet calming section; (7) Overflow weir; (8) D.C. power supply; (9) Plastic control valve; (10) Bypass

The third section of the reactor (outlet section) had a height of $0.25 \mathrm{~m}$ and was fitted with an overflow weir where the solution leaves the reactor, this section was packed with glass spheres of $0.016 \mathrm{~m}$ diameter.

The flow circuit consisted of $0.4 \times 0.4 \times 0.4 \mathrm{~m}^{3}$ glass storage tank connected to a $187 \mathrm{~W}$ plastic centrifugal pump for circulation of the solution between the reactor and the storage tank, solution velocity in the reactor was controlled by means of a bypass and was measured by a calibrated rotameter. Superficial solution velocity ranged from 0.0011 to $0.0063 \mathrm{~m} \mathrm{~s}^{-1}$. The electrical circuit consisted of $10 \mathrm{~V}$ $\mathrm{dc}$ power supply with a voltage regulator, the power supply was connected in series with a digital ammeter and the cells, a digital voltmeter was connected in parallel with the cell to measure its voltage. The limiting current of the cathodic reduction of $\mathrm{K}_{3} \mathrm{Fe}(\mathrm{CN})_{6}$ was determined by increasing the current stepwise and measuring the corresponding cell voltage until the limiting current plateau was 
Table $1-$ Physical properties of the solution at $30^{\circ} \mathrm{C}$

\begin{tabular}{|c|c|c|c|c|}
\hline Solution Composition & $\begin{array}{c}\rho \\
\left(\mathrm{kg} \mathrm{m}^{-3}\right)\end{array}$ & $\begin{array}{c}\mu \cdot 10^{3} \\
\left(\mathrm{~kg} \mathrm{~m}^{-1} \mathrm{~s}^{-1}\right)\end{array}$ & $D \cdot 10^{10}\left(\mathrm{~m}^{2} \mathrm{~s}^{-1}\right)$ & $S c$ \\
\hline $0.01 \mathrm{M} \mathrm{K}_{3} \mathrm{Fe}(\mathrm{CN})_{6}+0.1 \mathrm{M} \mathrm{K}_{4} \mathrm{Fe}(\mathrm{CN})_{6}+1 \mathrm{M} \mathrm{NaOH}$ & 1004 & 0.9885 & 7.5 & 1253 \\
\hline $0.01 \mathrm{M} \mathrm{K}_{3} \mathrm{Fe}(\mathrm{CN})_{6}+0.1 \mathrm{M} \mathrm{K}_{4} \mathrm{Fe}(\mathrm{CN})_{6}+2 \mathrm{M} \mathrm{NaOH}$ & 1082 & 1.2304 & 6.24 & 1821 \\
\hline $0.01 \mathrm{M} \mathrm{K}_{3} \mathrm{Fe}(\mathrm{CN})_{6}+0.1 \mathrm{M} \mathrm{K}_{4} \mathrm{Fe}(\mathrm{CN})_{6}+3 \mathrm{M} \mathrm{NaOH}$ & 1116 & 1.5403 & 4.995 & 2778 \\
\hline
\end{tabular}

reached. In view of the high area of the anode compared to the cathode along with the high ferro/ferricyanide concentration ratio, the anode was taken as a reference electrode against which the cathode potential was measured ${ }^{17}$. Three different solution compositions were used in the present study, namely: $0.01 \mathrm{M} \mathrm{K} \mathrm{K}_{3} \mathrm{Fe}(\mathrm{CN})_{6}+0.1 \mathrm{M} \mathrm{K} \mathrm{K}_{4} \mathrm{Fe}(\mathrm{CN})_{6}+$ $1 \mathrm{~N} \mathrm{NaOH}, 0.01 \mathrm{M} \mathrm{K}_{3} \mathrm{Fe}(\mathrm{CN})_{6}+0.1 \mathrm{M} \mathrm{K}_{4} \mathrm{Fe}(\mathrm{CN})_{6}$ $+2 \mathrm{~N} \mathrm{NaOH}$, and $0.01 \mathrm{M} \mathrm{K}_{3} \mathrm{Fe}(\mathrm{CN})_{6}+$ $0.1 \mathrm{M} \mathrm{K}_{4} \mathrm{Fe}(\mathrm{CN})_{6}+3 \mathrm{~N} \mathrm{NaOH}$.

All solutions were prepared using distilled water and A. R chemicals. Solution viscosity and solution density needed for data correlation were determined by an Ostwald viscometer and density bottle, respectively ${ }^{18}$, ferricyanide diffusivity was taken from the literature ${ }^{17,19}$. Table 1 shows the physical properties of the solutions at $30{ }^{\circ} \mathrm{C}$.

\section{Results and discussion}

Fig. 2 shows typical current - potential curve with a well-defined limiting current plateau. The limiting current obtained from these curves was used to calculate the mass transfer coefficient under different conditions according to the equation ${ }^{17}$

$$
\frac{I_{L}}{z F}=k A C \text {. }
$$

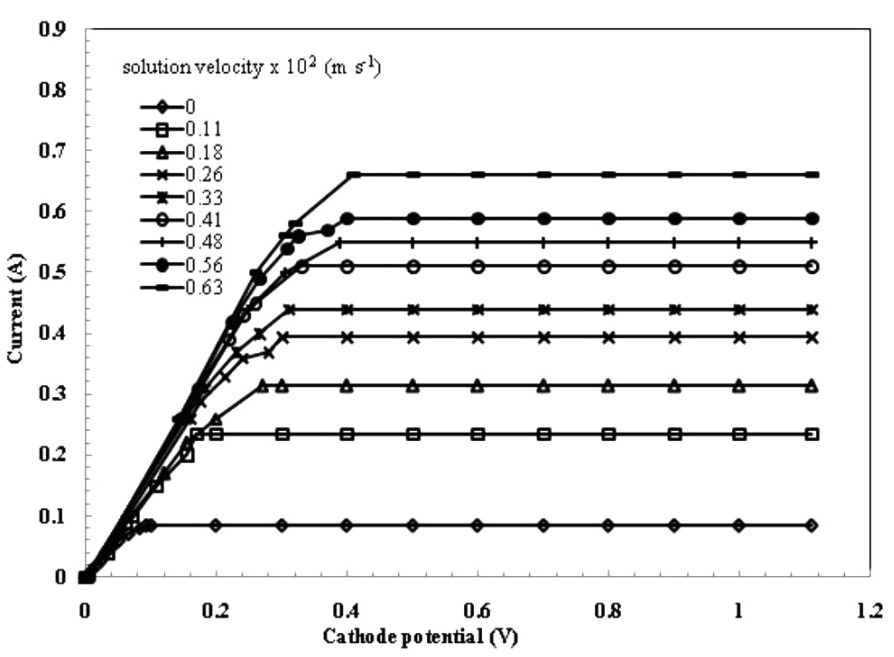

Fig. 2 - Typical polarization curves at different solution velocity (coil tube diameter $=0.01 \mathrm{~m}$, packing cylinder diameter $=0.008 \mathrm{~m}, \mathrm{Sc}=1821$
Fig. 3 shows that the mass transfer coefficient at the helical coil increases with increasing superficial solution velocity, according to the equation

$$
k=a V^{0.52}
$$
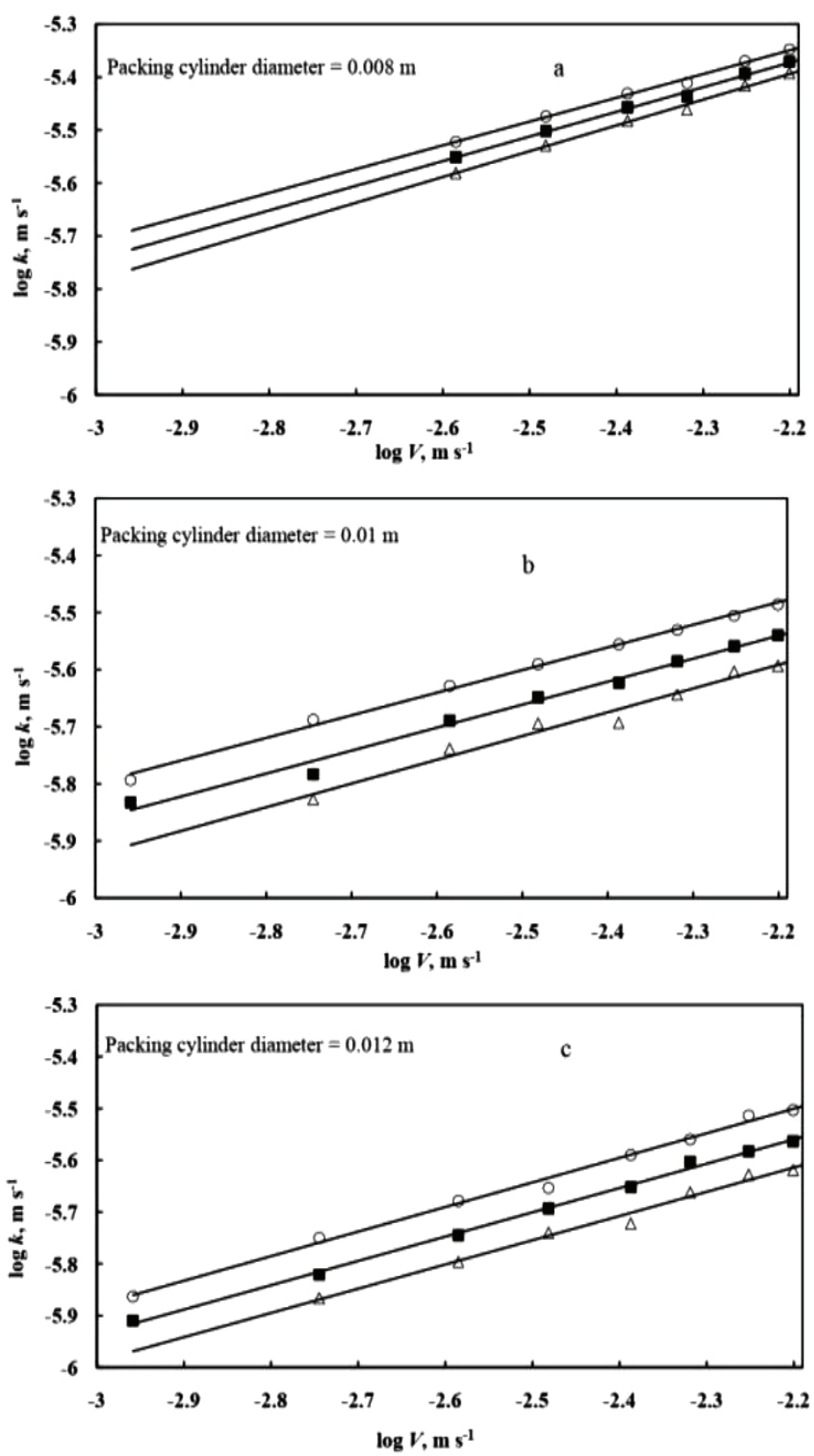

Fig. $3-\log k$ vs. $\log V$ at different Sc numbers $(\circ S c=1253$, - $S c=1821, \Delta S c=2778)$ and different packing cylinder diameter $($ coil tube diameter $=0.006 \mathrm{~m}$ ) 
The exponent 0.52 agrees fairly with the value 0.5 predicated from the hydrodynamic boundary layer at horizontal cylinders, according to which the thickness of the hydrodynamic boundary layer and the underlying diffusion layer $(\delta)$ surrounding the helical coil tube decrease with increasing solution velocity $6,7,20$.

Fig. 4 shows the effect of inert packing particle size on the mass transfer coefficient at the helical coil, the mass transfer coefficient decreases with increasing particle size diameter, according to the equation

$$
k=a_{1} d_{p}^{-2.32}
$$

The increase in the mass transfer coefficient with decreasing packing particle size is attributed to: (i) The increase in the interstitial solution velocity as a result of decreasing the available cross-sectional area of the reactor through which the solution flows. In other words, as the particle size decreases, the bed porosity $(\in)$ decreases with a consequent increase in the interstitial velocity $\left(V_{i}\right)$, according to the equation

$$
V_{i}=\frac{V}{\epsilon}
$$

The superficial solution velocity $(V)$ is obtained by dividing the volumetric flow rate by the cross-section of the empty container.

(ii) As the particle size decreases (preferential solution flow at the container wall rather than through the bed), channeling decreases with a consequent increase in the uniformity of flow through the bed ${ }^{21}$.

The present finding that the mass transfer coefficient at the coil surface increases with decreasing packing particle size is consistent with the results of other authors who used vertical cylinders and plates as a transfer surface ${ }^{8,11,22}$.

To demonstrate the role of bed packing particle in enhancing the rate of mass transfer at the imbedded helical coil, a comparison of the present data with the data obtained at helical coil under single-phase flow in a cylindrical vessel without packing by Abdel-Aziz et al. ${ }^{14}$, the authors correlated their data using the equation

$$
S h=0.084 S c^{0.33} R e^{0.54}
$$

Helical coil tube diameter was used as a characteristic length in calculating $S h$ and $R e$ by the authors. Fig. 5 shows that, for a given set of conditions, the present data lie above the data obtained in unpacked reactor. The enhancing effect of the packing particles is attributed to the favorable hydrodynamic conditions induced by the packing particles, namely: (i) the formation of turbulent wake behind
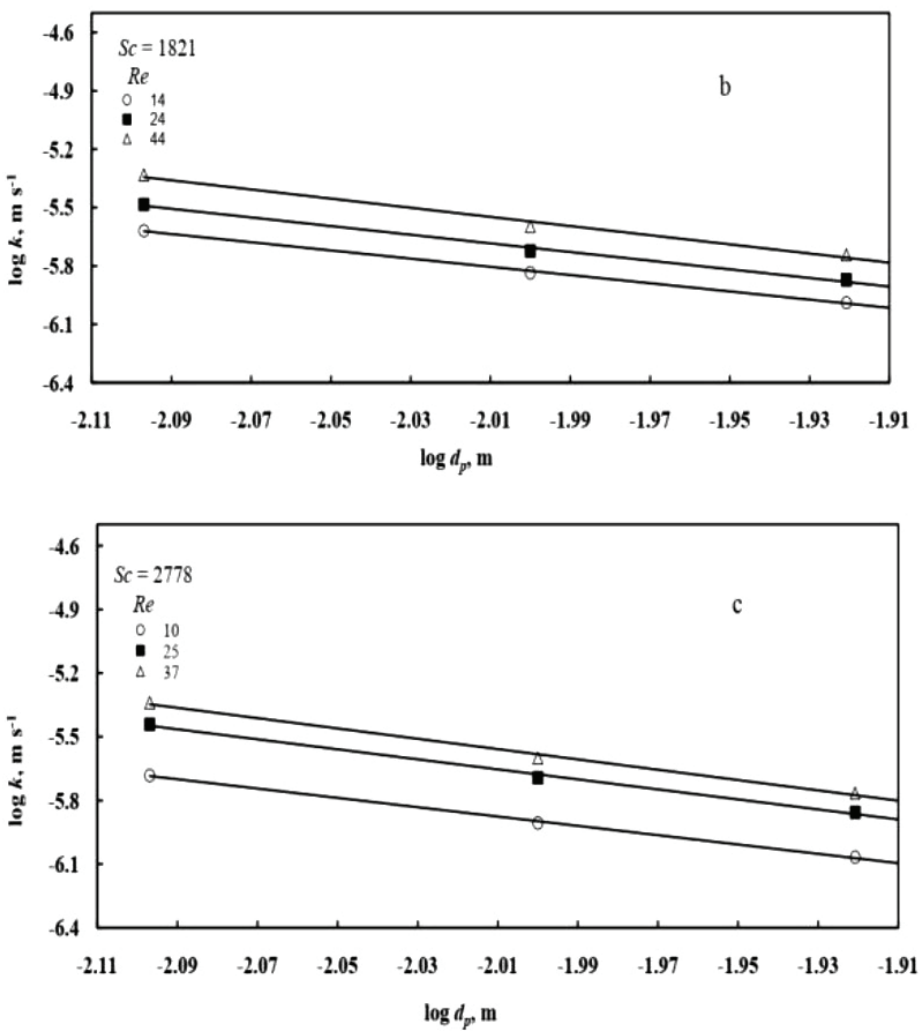

Fig. $4-\log k$ vs. $\log d$ at different Re and Sc (Coil tube diameter $=0.01 \mathrm{~m}$ )

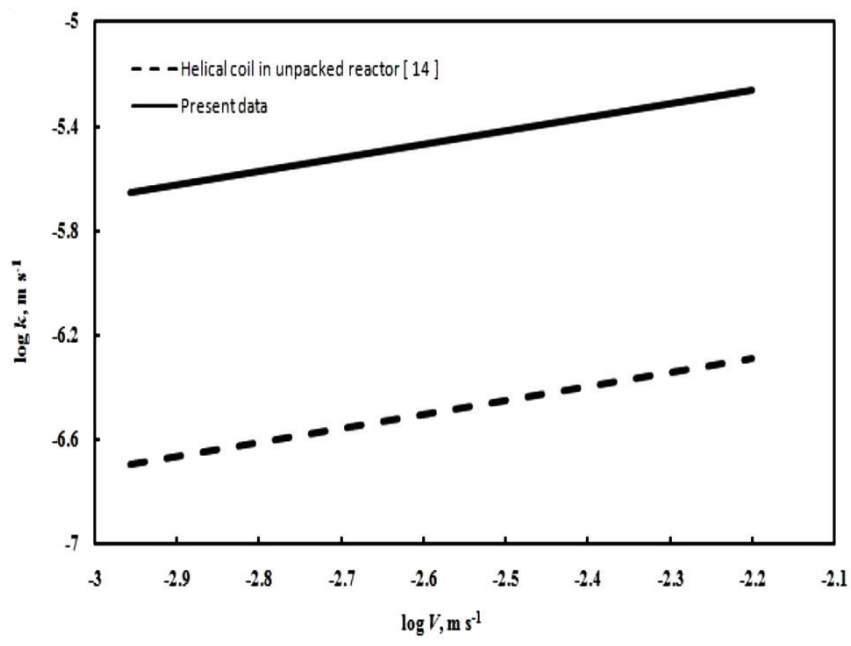

Fig. 5 - Comparison between the mass transfer behavior of a helical coil in a packed and unpacked reactor (coil tube diameter $=0.016 \mathrm{~m}$, packing cylinder diameter $=0.008 \mathrm{~m}, \mathrm{Sc}=$ 1253) 

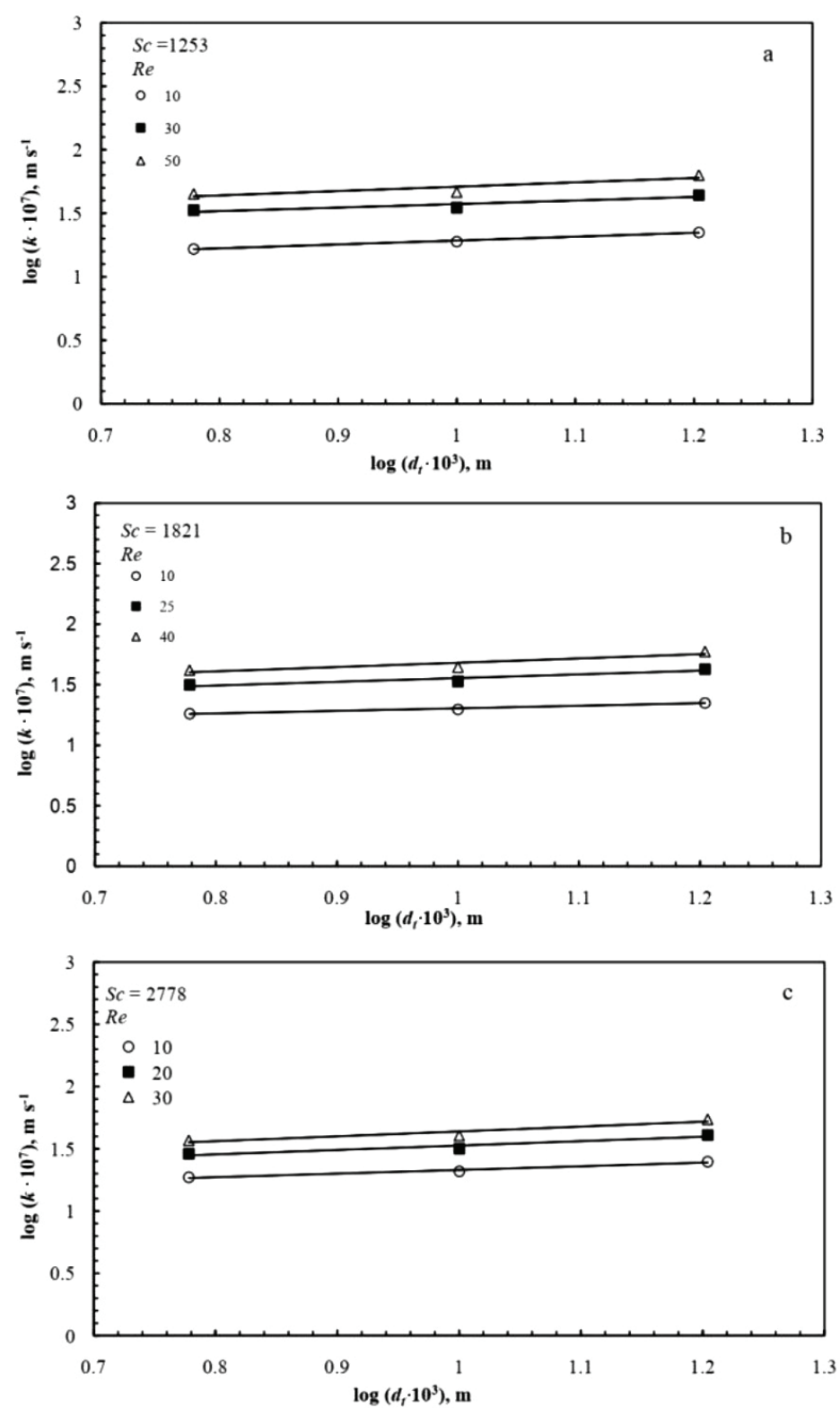

Fig. $6-\log k$ vs. $\log d_{t}$ at different Re and Sc (Coil tube diameter $=0.008 \mathrm{~m}$ )

each particle as a result of boundary layer separation from the particles beside the increase in the interstitial solution velocity as a result of the decrease in the available cross-sectional flow area of the container, (ii) the presence of packing particles around the helical coil tube disrupts the continuity of the developing hydrodynamic boundary layer around the helical coil tube, the repeated buildup and destruction of the hydrodynamic boundary layer, and the underlying diffusion layer at points of contact between the coil and the packing particles decreases the average thickness of the diffusion layer and increases the rate of mass transfer.

Fig. 6 shows the effect of helical tube diameter on the mass transfer coefficient. The data show that coil tube diameter has a negligible effect on the mass transfer coefficient probably because of the turbulent nature of the flow surrounding the helical coil $^{6,7,20}$ as a result of turbulent wake formation behind packing particles. Another possible explanation for the effect of helical tube diameter on the rate of mass transfer is that tube diameter under the present conditions has two opposing effects: (i) The average diffusion layer thickness tends to increase with increasing tube diameter ${ }^{6,7,20}$. This effect should lower the average mass transfer coefficient at the helical coil $(k=D / \delta)$. (ii) As the diameter of the coil increases the volume occupied by the coil increases, which contributes to lowering the available flow cross-sectional area (along with the packing) with a consequent increase in the interstitial velocity and the mass transfer coefficient. The finding that helical tube diameter has a little effect on the mass transfer coefficient may suggest that the two opposing effects balance each other.

An overall mass transfer correlation was envisaged in terms of the dimensionless groups $S h, S c$, and $R e$ usually used in correlating mass transfer under forced convection, an extra dimensionless group $\left(d_{\mathrm{p}} / d\right)$ was used to account for the effect of packing particle diameter. Fig. 7 shows that the present data for the conditions $1253<S_{c}<2778,6<R e<80$, and $0.044<\left(d_{\mathrm{p}} / d\right)<0.067$ fit the equation

$$
S h=7.14 \cdot 10^{-4} S c^{0.33} R e^{0.52}\left(\frac{d_{\mathrm{p}}}{d}\right)^{-2.32}
$$

with an average deviation of $\pm 16.81 \%$ and a standard deviation of $10.02 \%$, where $d_{\mathrm{p}}$ is the packing particle diameter, and $d$ is the container diameter. $R e$ was calculated using particle diameter $d$ as a characteristic length, while $S h$ was calculated using

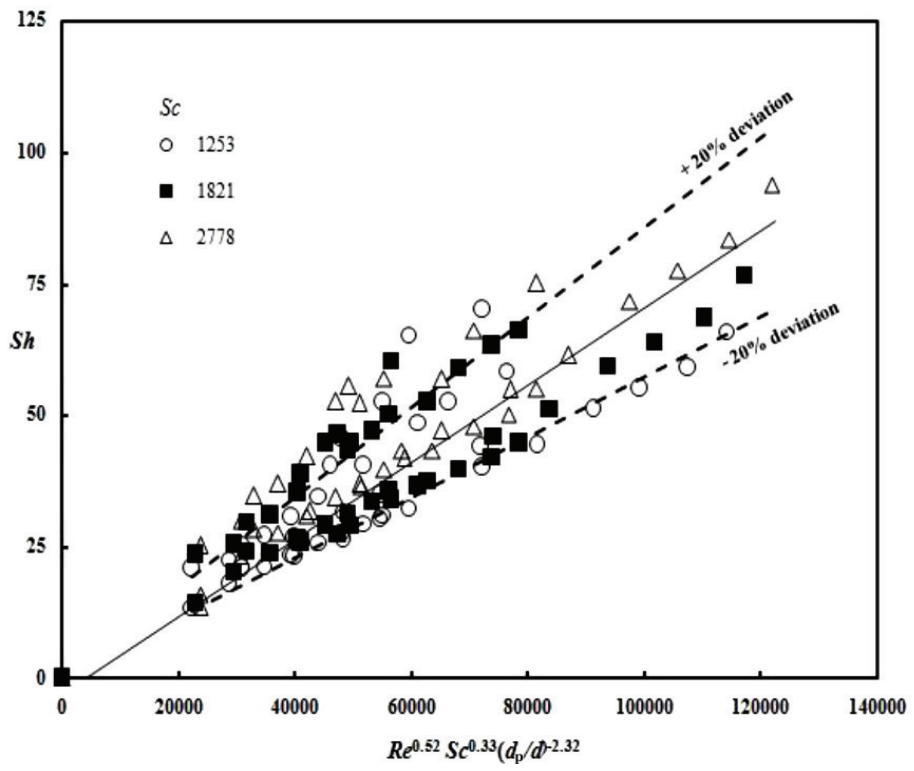

Fig. 7 - Overall mass transfer correlation for a helical coil imbedded in an inert fixed bed of cylinders 
coil tube diameter $d_{t}$ as a characteristic length. In obtaining the above equation, the exponent of $S c$ was fixed at 0.33 following previous theoretical and experimental mass transfer studies ${ }^{6,7,20}$. Although the analogy between heat and mass transfer is established in case of simple geometries, such as tubes, it is unsafe to assume that the analogy is valid under the present complex situation, and therefore, equation (7) cannot be used exactly to predict the heat transfer coefficient at the helical coil surface because of the difference in heat and mass transfer mechanisms under the present conditions. Mass is transferred between the coil and the bed by convection and diffusion, while heat transfer between the coil and the bed takes place by convection, thermal diffusion, and conduction between the bed particles and the coil. It is certain that the rate of heat transfer between the bed and the coil will be enhanced by turbulence generation and thermal conduction by the particles contacting the coil. A future heat transfer study is needed to quantify the rate of heat transfer between the bed and the helical coil.

\section{Conclusions}

The present results show that a helical coil imbedded in an inert fixed bed of cylinders can form the basis of a continuous high space-time yield electrochemical and catalytic reactor with a built-in heat transfer facility. The reactor is suitable for conducting exothermic diffusion-controlled liquid solid reactions that need rapid cooling, such as electro-organic synthesis involving heat-sensitive products and immobilized-cell biochemical reactions, where the outer surface of the coil acts as an electrode or a catalyst support, and the inner surface of the coil acts as a cooler. The high rate of mass transfer induced by the turbulence promoter and the high residence time arising from the low feed rate used in the present work combine to increase the degree of conversion per pass.

The dimensionless mass transfer correlation obtained in the present study can be used to scale up and operate the present reactor. To increase the productivity of the present catalytic reactor, a number of coaxial (parallel) helical coils of different coil diameter can be used in practice.

Although the productivity of the imbedded helical coil is about 11 times the unimbedded helical coil, it is expected that the pumping power, in the case of the imbedded coil, would be higher than that of the unimbedded coil. Accordingly, future studies should address this issue to make sure that the benefits of increasing the rate of production by fixed bed turbulence promoters outweigh the extra cost incurred by the increase in pressure drop across the bed and pumping power.

In addition, future studies should deal with measuring the rate of heat transfer at helical coils imbedded in fixed beds to quantify the rate of heat transfer between the bed and the coil.

$$
\begin{array}{ll}
\text { No m e n c l a t u r e } \\
A & - \text { Cathode (coil) area, } \mathrm{m}^{2} \\
a, a_{1} & - \text { Constants } \\
C & - \text { Ferricyanide concentration, } \mathrm{mol} \mathrm{m}^{-3} \\
D & - \text { Diffusivity of ferricyanide, } \mathrm{m}^{2} \mathrm{~s}^{-1} \\
d & - \text { Container diameter, } \mathrm{m} \\
d_{\mathrm{p}} & - \text { Packing particle (cylinder) diameter, } \mathrm{m} \\
d_{t} & - \text { Coil tube diameter, } \mathrm{m} \\
F & - \text { Faraday's constant }\left(96485 \mathrm{C} \mathrm{mol}^{-1}\right. \text { ) } \\
I & - \text { Current, A } \\
I_{L} & - \text { Limiting current, A } \\
k & - \text { Mass transfer coefficient, } \mathrm{m} \mathrm{s}^{-1} \\
Q & - \text { Heat generated during electrolysis, } \mathrm{J} \\
R & - \text { Solution resistance, ohm } \\
S & - \text { Entropy, J K } \\
T & - \text { Temperature, K } \\
V & - \text { Superficial solution velocity, } \mathrm{m} \mathrm{s}^{-1} \\
V & - \text { Interstitial solution velocity, } \mathrm{m} \mathrm{s}^{-1} \\
z & - \text { Number of electrons involved in the reaction }
\end{array}
$$

\section{Dimensionless groups}

$$
\begin{aligned}
& S c \quad \text { Schmidt number }\left(\frac{\mu}{\rho D}\right) \\
& S h \quad \text { - Sherwood number }\left(\frac{k d_{t}}{D}\right) \\
& \text { Re } \quad \text { - Reynold's number }\left(\frac{\rho V d_{\mathrm{p}}}{\mu}\right)
\end{aligned}
$$

\section{Greek symbols}

$$
\begin{array}{ll}
\mu & - \text { Viscosity, } \mathrm{kg} \mathrm{m}^{-1} \mathrm{~s}^{-1} \\
\rho & - \text { Density, } \mathrm{kg} \mathrm{m}^{-3} \\
\epsilon & - \text { Bed porosity } \\
\delta & - \text { Diffusion layer thickness, } \mathrm{m} \\
\eta & - \text { Over potential, } \mathrm{V}
\end{array}
$$

\section{References}

1. Zewail, T. M., Zatout, A. A., El-Taweel, Y. A., Sedahmed, G. H., Liquid - solid mass transfer behavior of a vertical array of closely spaced horizontal tubes in relation to catalytic and electrochemical reactor design, Chem. Eng. Technol. 33 (2010) 121.

doi: https://doi.org/10.1002/ceat.200900311 
2. Anxionnaz, Z., Cabassad, M., Gourdon, C., Tochon, P. Heat exchanger/reactor (Hex reactors) concepts, technologies: State of the art, Chem. Eng. Processing 47 (2008) 2029. doi: https://doi.org/10.1016/j.cep.2008.06.012

3. Anxionnaz, Z., Cabassad, M., Gourdon, C., Tochon, P., Influence of the meandering channel geometry on the thermo-hydraulic performance of intensified heat exchanger/ reactor, Chem. Eng. Processing 73 (2013) 67. doi: https://doi.org/10.1016/j.cep.2013.06.012

4. Soliman, M. S., Nosier, S. A., Hussein, M., Sedahmed, G. H., Mobarak, A. A., Mass and heat transfer behavior of a new heterogeneous stirred tank reactor with serpentine tube baffle, Chem. Eng. Res and Design 124 (2017) 211. doi: https://doi.org/10.1016/j.cherd.2017.06.012

5. Baily, J. E., Ollis, D. F., Biochemical Engineering Fundamentals, $2^{\text {nd }}$ edition, McGraw Hill, New York, 1987, 292

6. Walsh, F. C., A first course in electrochemical engineering, the electrochemical consultancy, Hants (U. K), 1993.

7. Fahidy, T. Z., Principles of electrochemical reactor analysis, Elsevier, New York, 1985.

8. Sedahmed, G. H., El-Taweel, Y. A., Konsowa, A. H., Abdel-Aziz, M. H., Mass transfer intensification in annular electrochemical reactor by an inert fixed bedunder various hydrodynamic conditions, Chem. Eng. Processing 50 (2011) 1122. doi: https://doi.org/10.1016/j.cep.2011.10.002

9. Sedahmed, G. H., El-Taweel, Y. A., Konsowa, A. H., Abdel-Aziz, M. H., Effect of packing geometry on the rate of mass and heat transfer at a vertical tube imbedded in fixed bed under single and two phase flow, Int. Commun. in Heat and Mass Transfer 48 (2013) 149.

doi: https://doi.org/10.1016/j.icheatmasstransfer.2013.08.002

10. Hutin, D., Storck, A., Coeuret, F., Local study of wall to liquid mass transfer in fluidized and packed beds. II mass transfer in packed beds, J. of Appl. Electrochem. 9 (1979) 361 .

doi: https://doi.org/10.1007/BF01112491

11. Storck, A., Coeuret, F., Mass transfer between a flowing liquid and a wall of an immersed surface in fixed and fluidized beds, Chem. Eng. J. 20 (1980) 149. doi: https://doi.org/10.1016/0300-9467(80)85035-0

12. Abdel-Aziz, M. H., Mansour, I. A. S., Sedahmed, G. H., study of the liquid-solid mass transfer controlled processes in helical tubes under turbulent flow conditions, Chem. Eng. Processing 49 (2010) 643. doi: https://doi.org/10.1016/j.cep.2009.06.004

13. Sedahmed, G. H., Shemilt, L. W., Wong, F., Natural convection mass transfer characteristics in relation to their use in electrochemical reactor design, Chem. Eng. Sci. 40 (1985) 1109 doi: https://doi.org/10.1016/0009-2509(85)85069-7

14. Abdel-Aziz, M. H., Nirdosh, I., Sedahmed, G. H., Mass and heat transfer at the outer surface of helical coil under single and two phase flow, Appl. Thermal Engineering 103 (2016) 713.

doi: https://doi.org/10.1016/j.applthermaleng.2016.04.146

15. Abdel-Aziz, M. H., Nirdosh, I., Sedahmed, G. H., Mass and heat transfer behavior of oscillating helical coils in relation to heterogeneous reactor design, AIChE J. 63 (2017) 3141. doi: https://doi.org/10.1002/aic.15614

16. Heo, J. H., Chung, B. J., Influence of helical coil tube dimensions open channel natural convection heat transfer, Int. J. of Heat and Mass Transfer 55 (2012) 2829. doi: https://doi.org/10.1016/j.ijheatmasstransfer.2012.02.043

17. Selman, J. R., Tobias, C. W., Mass transfer measurement by the limiting current technique, Adv. Chem. Eng. 10 (1978) 211. doi: https://doi.org/10.1016/S0065-2377(08)60134-9

18. Findlay, A., Ketchner, J. K., Practical physical chemistry, Longman London, 1961.

19. Bourne, J. R., Ava, P. D., Dossenbach, O., Post, T., Densities, viscosities and diffusivities in a queoussodium, hydroxide-potassium ferri- and ferrocyanide solution, J. Chem and Eng. Data 30 (1985) 160. doi: https://doi.org/10.1021/je00040a008

20. Incropera, F. P., Dewitt, D. P., Fundamentals of heat and Mass transfer, $3^{\text {rd }}$ edition, New York, 1990

21. Wang, Y. Y., Principles of packed bed electrochemical reactors, in: Cheremisionff, N. P. (Ed.), Handbook of heat and mass transfer, Vol. 12, Gulf publishing Co., London, 1986.

22. Sadik, E. R., Zewail, T., Konswa, A., Abd El-latif, M., Sedahmed, G. H., Effect of surface active pollutants on the rate of mass transfer controlled corrosion of reactors used in waste water treatment, Am. J. of Chem. Eng. 4 (2016) 92. doi: https://doi.org/10.11648/j.ajche.20160405.11 